\title{
Fostering TEAMWORK SKILlS USING COLLABORATION SOFTWARE IN ENGINEERING DESIGN EDUCATION
}

\author{
Gerd Gidion ${ }^{1}$ and Ralph O. Buchal ${ }^{2}$ \\ ${ }^{1}$ Karlsruhe Institute of Technology; ${ }^{2}$ Western University \\ 'sidion@kit.edu ; ${ }^{2}$ rbuchal@uwo.ca
}

\begin{abstract}
The ability to work in a professional team is an essential social competence of engineers, who must collaborate on common tasks, with shared goals. Social competence has many aspects that are difficult to define and evaluate. Based on a theoretical framework of social competence, we identify several specific attributes and indicators that can be used to develop and evaluate social competencies related to teamwork in professional engineering. The specific attributes are professional project management, team interaction and professional documentation. These attributes are fostered in several ways. Team communication and coordination is fostered through explicit team roles (e.g. moderator, secretary, project manager, etc.), explicit requirements for project planning and scheduling, requiring professional documentation, and using computer tools to support these collaborative activities. These strategies develop competencies in communication, teamwork, presenting and understanding information, and using collaboration tool. At a higher level, these competencies contribute to each team member understanding the roles and contributions of the other team members, developing a shared understanding of the team's position, and negotiating within the team and with external parties to reach sound decisions and conclusions. This paper describes and compares experiences using collaboration software tools to support teamwork activities in undergraduate design projects at Karlsruhe Institute of Technology (KIT) and Western University. Collaboration tools include Microsoft Project, Microsoft SharePoint, Sakai, and wikis. The paper discusses the selection of appropriate tools, the formalization of their use, and methods used to evaluate student competence.
\end{abstract}

Keywords: design education, teamwork and collaboration, collaboration software, social competence, project management

\section{INTRODUCTION}

Teamwork and communication are recognized to be essential skills for engineers. To develop these skills, it is important to develop social competence of engineering students $[1,2,3,4]$. However, it is difficult to determine exactly what needs to be taught, and how to teach it. In order to make progress, it is necessary to establish a conceptual framework, which can be used as a basis for defining specific objectives, indicators, and educational strategies.

\section{SOCIAL COMPETENCE DEFINED}

Euler and Bauer-Klebl define social competence as the ability to interact purposefully with other people about factual, social and personal topics in specific types of situations [5]. They assert that (according to Kanning [6]) social competence can be differentiated into general and situation-specific aspects. General aspects of social competence (e.g. team leading) must be distinguished from situational elements (e.g. active listening in a team conversation), and rare situations (e.g. conflicts) from routine situations (e.g. to apologize for a delay). As a consequence, individuals cannot be seen as socially competent in general, but only in the context of their behavior in a range of specific situations.

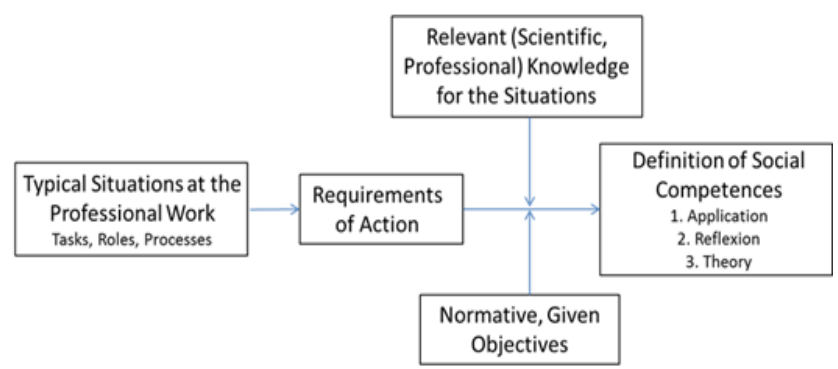

Figure 1. Procedure to identify and define relevant social competences (modelled after [5]).

Beginning from a model proposed by Euler and BauerKlebl [5], a modified approach can be identified (Figure 1). Starting points of this approach are typical situations that emerge in the work of an engineer, especially when team activities happen. These situations are defined by the given job tasks, the systems and procedures of work in the company and the roles of the involved actors. The professional situations are based on requirements of the 
given task and can be solved by applying professional action (work). If the practical requirements from the situation at work are transferred into contents of higher education, they have to be grounded and enriched with (theoretical) knowledge and normative contents and objectives that come from the disciplinary community (engineering).

\section{LEARNING SOCIAL COMPETENCE AND TEAMWORK SKILLS}

For higher education, three levels of (teaching and) learning must be differentiated:

- learning to apply something practically (e.g. to act and cooperate in a working team)

- learning to reflect about practical situations and experiences (e.g. to analyse team procedures and activities from a professional perspective and to orientate the appropriate reaction or consequences)

- learning to professionalise ones work based on theoretical analysis and findings (e.g. to organise professional teams utilizing academic knowledge about group dynamics)

If social competence - and specifically teamwork ability - is to be fostered within the engineering curriculum, the initial focus should be on practical applications, with reflection about team procedures. Theoretical aspects of social competence are usually not discussed, since this is not considered a core engineering subject. Nevertheless the objectives of teaching social competences in engineering have to be deduced from scientific knowledge. In this case the objectives are deduced at first from the analysis of the requirements of the work of a professional engineer in a company.

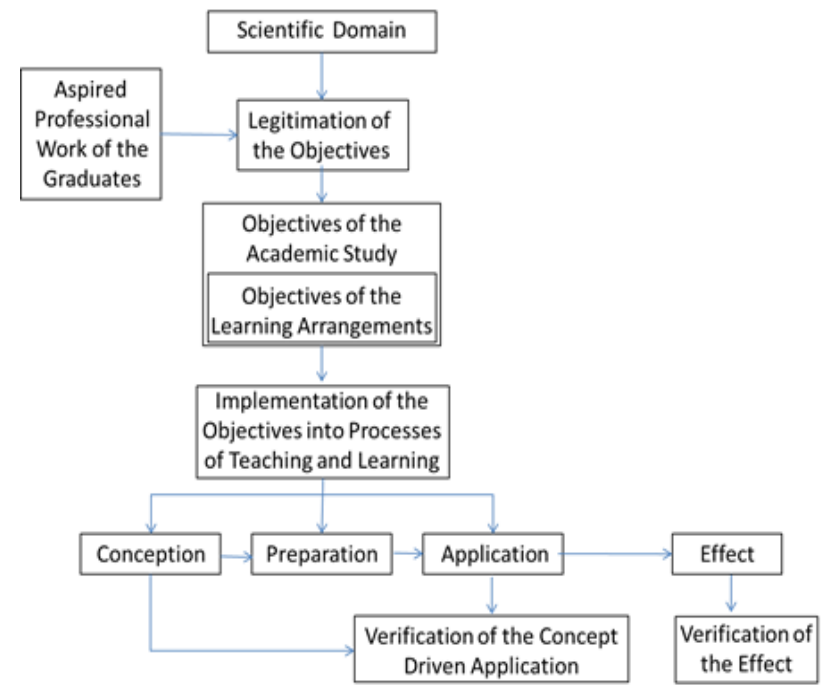

Figure 2. Schematic figure of the definition of objectives, fostering and proof of effects.

The objectives of social competence apply across the curriculum. This definition provides a framework for specific objectives in different courses, modules and other learning activities. The realisation of the objectives in the process of teaching and learning has to integrate the conception, the preparation and the application of effective educational strategies. These elements are the primary focus for demonstrating adequate fostering of social competence.

It has to be demonstrated that the relevant competence is considered in the course based on a defined concept, that this is utilized in the preparation of the teaching / learning arrangements by didactical oriented interventions, and that the conceptualized and prepared elements of the course are realized within the actual activities or processes. It is difficult to demonstrate that these interventions have a positive effect on social competencies of practicing engineers after graduation, since this requires analysis of their professional work.

\section{KIT EXPERIENCE}

Conception, realization and proof of effects should be described in the following regarding a course in design development at the Karlsruhe Institute of Technology (KIT).

The concept of the KIT Institute of Product Engineering IPEK (within the program of mechanical engineering) assumes that teamwork is an essential factor for success in modern professional engineering work. Engineers should be able to: negotiate face-to-face in a professional style; take over different roles (e.g. as team leader, specialist in a team, coordinator); and utilize professional (software) tools to facilitate and support teamwork. It is important to collaborate effectively, to explain one's own work to the colleagues, to pay attention to the deliverables of the other team members and to reach a common goal. The professional engineer has to be able to represent and elucidate the contribution of every team member to a superior, a customer or an external partner.

Within the framework of a project-based approach of the Karlsruhe Education Model for Product Development KaLeP $[7,8]$, different competencies are fostered in the context of professional situations concerning design projects in mechanical engineering. 


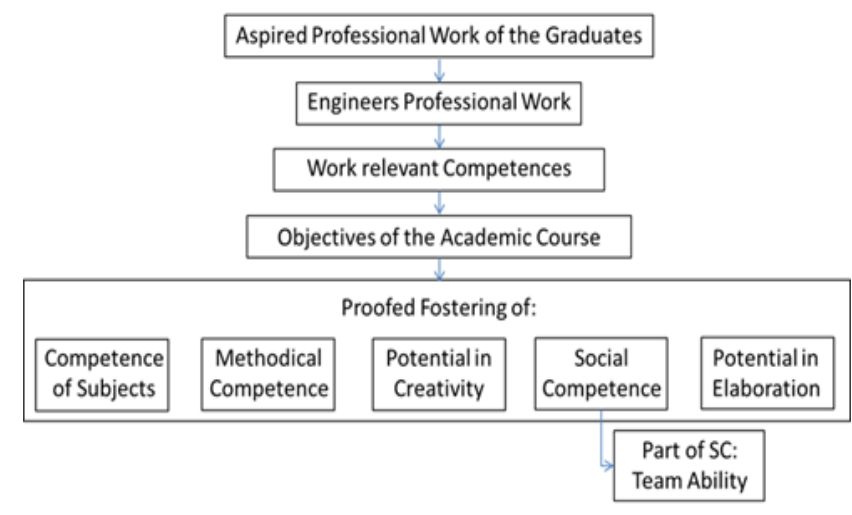

Figure 3. The structure of defined competencies within the KALEP approach.

According to Albers and Matthiesen, "The objective of any academic education in engineering at the university has to be - besides of the teaching / learning of essential knowledge and the ability for academic work - the development of the ability to work as a professional engineer in the industry [9]".

In this connection it is desired to foster disciplinary subject competence, methodical and social competence of the future engineers in a verifiable way, as well as fostering the potential of creativity and elaboration (Figure 3). Therefore didactical interventions and arrangements have to be devised and their effectiveness has to be validated. Teaching in the areas of disciplinary subjects and methods is well supported by established knowledge and practices. However, the area of social competence for engineers is a relatively new challenge. Following the KaLeP-definition, the ability to act professionally within a team is one of the most important aspects of social competence. Teamwork ability is characterized by three engineering-relevant aspects: representing the team; utilizing teamwork tools; and direct communication in the team. These highlighted aspects are specifically fostered in the course related to typical situations and routines of engineering work. This is only a subset of the many aspects involved in real engineering teamwork, but it is a good baseline to start with.

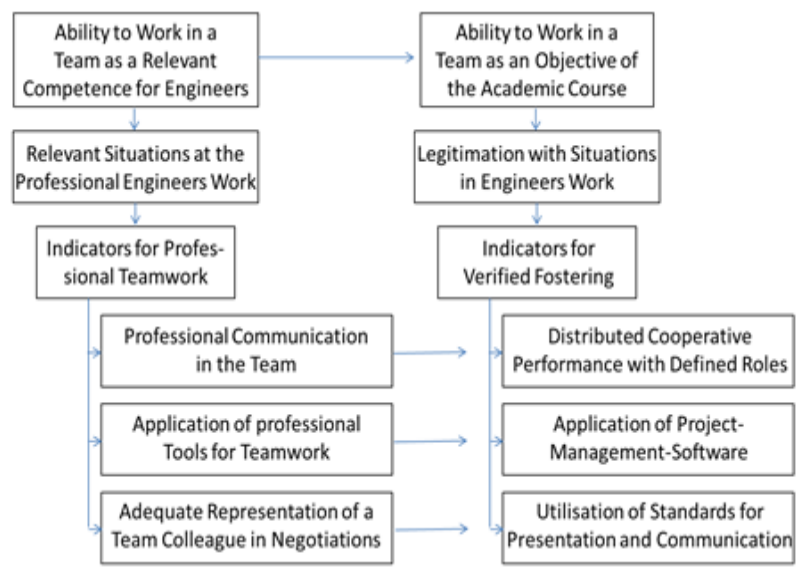

Figure 4. Professional competencies and corresponding learning activities.

Each member of a professional engineering team must be able to explain his/her own subtask - e.g. a specific investigation - and to deliver the results in an adequate form to other team members, so that they can use these results for their ongoing work. The results must be documented clearly and completely so that they are understandable in an unambiguous way by every colleague, without requiring additional explanation. Documentation must use standard disciplinary language, standard and defined symbols, standard engineering drawings, and any other necessary documentation. This documentation allows an engineer to explain the work of a colleague to a third party, when the colleague is not available. A typical situation would be for a single team member to present the work of the entire team to a customer, client or manager. Another situation would be to continue the work of a colleague who has left the team.

Negotiation and decision-making are essential higher level activities of an engineering team, supported by communication, documentation and collaboration tools. Negotiation is essentially a discussion or dialog examining issues and alternatives, and presenting arguments and perspectives, in order to reach an agreement or decision about a course of action. Negotiations can be variable in their complexity: a consensual talk will be easier to moderate or handle compared to an emergency meeting, a controversial conversation with a customer or a discussion about a project that runs out of schedule.

The level of professionalism can be evaluated in situations like these using relevant indicators. In the KaLeP approach the responsible instructors take the following three main indicators as the dominant indicators: (1) the professional communication in team meetings; (2) the adequate representation of the team in conversation with customers and superiors; and (3) the application of professional teamwork tools (Figure 3).

CEEA13; Paper 73

Montreal, QC; June 17-20, $2013 \quad-3$ of 6 - 
Therefore these indicators are targeted, fostered and evaluated within the KaLeP-course:

1. Team competence by professional understanding in direct communication is fostered utilising explicit differentiated roles in the team like moderator, secretary, speaker, specialist for details, project manager). The focus is primarily on face-to-face meetings.

2. The ability to stand for the team in negotiations is fostered by using standards to produce, explain and evaluate professional engineering documentation including technical drawings and reports;

3. The ability to utilize tools for teamwork is fostered by using established software for collaborative work.

This third aspect is realised with Microsoft (MS) Project and web-based shared project workspaces (MS SharePoint). Competence with computer based tools is a basic requirement for success in engineering practice. MS Project is an industry-standard project management tool. By working with MS Project, the activities of every team member become visible for the others. Consequently, the tasks of the team members can be coordinated in time and content. MS Project constrains the team to plan the process with milestones, and to track their different contributions. It enables the team to observe the process and adapt the progress to the conditions and facts. Paying attention to defined regularities using MS Project can be identified as an indicator for professional teamwork.

Whilst MS Project is a tool for project management and planning of teamwork, emerging collaboration tools like MS SharePoint provide a shared workspace for computer based teamwork. Within these shared workspaces, team members can share project documentation and documents, collaboratively author documents, discuss topics in written style, and publish results for the group. These new collaboration tools are being adopted rapidly by industry. Student activities can be monitored, and used as indicators of competency in professional teamwork. To acquire the ability to work with teamwork tools, students are required to use MS SharePoint to collaborate and share results in a concrete team project.

This content is a defined part of the curriculum comparable to technical core contents of mechanical engineering. The utilisation of the teamwork tools by the students is a necessity in the same way as the solving of the technical tasks in the project. Usage of the teamwork tools is an aspect of evaluation, comparable with the evaluation of the technical solution of the project.

\section{WESTERN UNIVERSITY EXPERIENCE}

\subsection{Social Competence and CEAB Graduate Attributes}

In Canada, the Canadian Engineering Accreditation Board (CEAB) Graduate Attributes [10] describe the same competencies identified in the KALEP approach and shown in Figure 2. Social competence is embodied in several of the CEAB Attributes, including:

Use of Engineering Tools. An ability to create, select, apply, adapt, and extend appropriate techniques, resources, and modern engineering tools to a range of engineering activities, from simple to complex, with an understanding of the associated limitations.

Individual and Team Work. An ability to work effectively as a member and leader in teams, preferably in a multi-disciplinary setting.

Communication Skills. An ability to communicate complex engineering concepts within the profession and with society at large. Such abilities include reading, writing, speaking and listening, and the ability to comprehend and write effective reports and design documentation, and to give and effectively respond to clear instructions.

Professionalism. An understanding of the roles and responsibilities of the professional engineer in society, especially the primary role of protection of the public and the public interest.

Ethics and equity. An ability to apply professional ethics, accountability, and equity.

Economics and project management. An ability to appropriately incorporate economics and business practices including project, risk and change management into the practice of engineering, and to understand their limitations.

Every Canadian engineering program is required to develop these abilities, and to demonstrate that graduating engineers are competent in these attributes. Design projects, especially capstone design, are one of the best places to develop and demonstrate these attributes.

\subsection{Capstone Design in Mechanical Engineering}

All students in Western's Mechanical Engineering program are required to complete a team-based capstone design project. Every team must demonstrate the use of a systematic design process, and application of relevant engineering knowledge and methods to model and validate design concepts.

Project management, communication and teamwork skills are developed in several ways. Each team is required to submit a detailed proposal at the beginning of the project. The proposal must include a detailed 
description of project scope, milestones, schedule, work breakdown structure, and budget. Teams meet weekly with a faculty advisor to review progress and next steps. Teams also meet to work on the project and coordinate tasks. At the conclusion of the project, teams must submit a professional-quality design report, with all supporting design documentation including digital files and CAD models. The documentation must be sufficient to allow the project to be fully understood, and to be continued by others if appropriate.

\subsection{Use of software tools}

Project management is an important component of these team projects. Students are introduced to the basics of project management in previous years, but they typically use ad hoc and very basic tools to manage projects. MS Project is one of the most widely used and capable tools available for project management. MS Project is installed in the undergraduate engineering computer labs, but students and faculty do not have the software on their own computers. As a consequence, lab computers must be used to view and update the schedules. This is a major inconvenience, and it is impractical to require all students and faculty to obtain and use MS Project on their own computers.

A search was done for web-based project management tools, with limited success. Most web-based collaboration tools provide only the most basic project management capabilities, typically limited to a team calendar and perhaps a task list. MS SharePoint was evaluated in detail, but was not available for deployment in the past academic year. SharePoint offers project management capabilities that are better than most, but still not as comprehensive as MS Project.

SharePoint was also considered for use as a collaboration platform. It is among the best available tools, and is widely used in industry, but due to the need for IT support it was not possible to use it for more than preliminary testing.

Western University has recently adopted the opensource Sakai platform as a collaboration and learning environment. Its primary use has been for course management, but it is also a very powerful collaboration tool for projects. Sakai has many collaboration features including: document sharing, calendars, discussion forums, wikis, and integrated messaging.

Sakai project sites were created for each design team, and teams were encouraged to use these sites to support their work. In particular, students were required to post weekly individual progress reports using Sakai discussion forums.

Sakai was also used for course management. Students were required to upload all deliverables to Sakai on the specified due dates. Submitted documents were annotated by faculty advisors using the commenting tools in either
MS Word or Acrobat Reader, and the commented documents were returned to the students along with their marks. No hardcopy reports were required.

Many mechanical engineering projects involve extensive CAD modeling, and managing shared CAD models is problematic. Due to the complex interdependencies between different files in a CAD model, conventional file sharing systems are inadequate to manage this data. Industry uses Product Data Management (PDM) systems for managing shared CAD models. We followed industry practice by using SolidWorks Workgroup PDM for student design projects. Workgroup PDM projects were set up for each team, and students were encouraged to use this tool.

\subsection{Observations}

The use of tools was sporadic due to many factors. The use of most of these tools was encouraged but optional, and many students chose not to use them.

Students don't normally share their working methods with faculty advisors, so it is difficult to have a complete picture of their methods. Students tend to be uncomfortable sharing work-in-progress, and share only the required deliverables.

Students used a variety of methods to collaborate, including various combinations of the following:

- Face-to-face meetings

- Physical design notebooks

- Private emails between individual team members

- $\quad$ Social networking tools like Facebook

- Text messaging

- Cloud-based document sharing tools including Google Docs, Dropbox, and Microsoft Skydrive

- Cloud-based collaborative document editing tools, particularly Google Docs

Students are not experts at using computer tools to support collaboration. Tools are typically used in an ad hoc fashion, rather than following emerging best practices. The use of these tools is usually not visible to faculty advisors, since students consider this to be for their private use only. Team communication and interaction tends to change if the team is being observed.

Implementation and use of software tools to support team projects typically requires institutional IT support as well as funding for software licensing, and these can be significant barriers. Tools like PDM and SharePoint require considerable IT support to install and administer, and as a consequence these tools are found at very few educational institutions. The importance and capabilities of these tools are not well understood by academics, so it is difficult to make a case for their use. 


\section{CONCLUSIONS}

While there are minor differences in terminology, the need to identify, develop and evaluate social competence is widely accepted. KIT and Western University have identified similar learning objectives, similar approaches and similar software tools to support and develop skills in the context of a professional engineering team. Existing and emerging software tools provide powerful new ways of collaborating, but their adoption is slow due to the requirement for significant IT support, and resistance of students (and faculty) to adopting new and untested ways of working.

\section{References}

[1] E. F. Crawley, J. Malmqvist, S. Östlund, D. R. Brodeur, (2007): Rethinking Engineering Education - The CDIOApproach. New York: Springer Science, 2007.

[2] European Network for Accreditation of Engineering Education, EUR-ACE syllabus, EUR-ACE Framework Standards for the Accreditation of Engineering Programmes, 2005, Available as of May 3, 2013 from http://www.ihep.org/assets/files/gcfp-files/EURACESTANDARDS.pdf.

[3] H. Junge, "Projektstudium zur Förderung beruflicher Handlungskompetenzen in der Ingenieurausbildung." Journal Hochschuldidaktik, Jg. 20, Heft 2. S.24-26, 2009, available as of May 3, 2013 from http://www.zhb.tudortmund.de/hd/fileadmin/JournalHD/2009_2/2009_2_Jung e.pdf

[4] A. Wittek, H.-R. Ludwig, I. Behr, "Synoptische Darstellung Empirischer Studien zum Kompetenzbegriff für die Entwicklung modularisierter Ingenieurstudiengänge”, Global Journal of Engineering. Education, UICEE Vol. 9, No. 3, S. 275-282, 2005, available as of May 3, 2013 from http://www.wiete.com.au/journals/GJEE/Publish/vol9no3/W ittek.pdf

[5] D. Euler, A. Bauer-Kleb, “Bestimmung und Präzisierung von Sozialkompetenzen. Theoretische Fundierung und Anwendung für die Curriculumentwicklung,” Zeitschrift für Berufs- und Wirtschaftspädagogik, Band 104, Heft 1. Stuttgart: Franz Steiner, S. 16-47, 2008.

[6] U. P. Kanning, Diagnostik sozialer Kompetenzen. Göttingen: Hogrefe. S. 19 ff., 2003

[7] Albert Albers, Norbert Burkardt, Tobias Düser, "More than Professional Competence - The Karlsruhe Education Model for Product Development (KaLeP).” 2nd International CDIO Conference. Linkoping, Sweden: Linkoping University, 2006.

[8]Albert Albers, Norbert Burkardt, Tobias Düser, "Competence-profile oriented education with the Karlsruhe Education Model for Product Development (KaLeP)." World Transaction on Engineering and Technology Education, Vol. 5, No. 2, 2006.
[9] Albert Albers, Sven Matthiesen, "Neue Lehrmodelle zur Ausbildung kreativer Konstrukteure. Das Karlsruher Lehrmodell für Produktentwicklung - KaLeP, ” 4. Deutscher Konstrukteurstag. Bochum: VDI, 2000.

[10] Accreditation Criteria and Procedures, Canadian Engineering Accreditation Board, Canadian Council of Professional Engineers, 2012. 